\title{
Review of Optimization Dynamically Applied in the Construction and the Application Potential of ICT
}

 \\ College of Civil Engineering, Tongji University, Shanghai 200092, China; 2010212@tongji.edu.cn (B.L.); \\ yangbin@tongji.edu.cn (B.Y.); jzx@tongji.edu.cn (J.X.); zhangbinghan@tongji.edu.cn (B.Z.); \\ wangzhichen@tongji.edu.cn (Z.W.); 2032594@tongi.eud.cn (M.D.) \\ * Correspondence: zhudayu2001@163.com
}

check for

updates

Citation: Liu, B.; Yang, B.; Xiao, J.; Zhu, D.; Zhang, B.; Wang, Z.; Dong, M. Review of Optimization

Dynamically Applied in the

Construction and the Application Potential of ICT. Sustainability 2021, 13, 5478. https://doi.org/10.3390/ su13105478

Academic Editor: José

Ignacio Alvarez

Received: 19 April 2021

Accepted: 10 May 2021

Published: 13 May 2021

Publisher's Note: MDPI stays neutral with regard to jurisdictional claims in published maps and institutional affiliations.

Copyright: (c) 2021 by the authors. Licensee MDPI, Basel, Switzerland. This article is an open access article distributed under the terms and conditions of the Creative Commons Attribution (CC BY) license (https:/ / creativecommons.org/licenses/by/ $4.0 /)$.
Abstract: Currently, construction projects are getting more complex, applying more information and communication technologies (ICT), while few studies use real-time data to dynamically optimize construction. The purpose of this article is to study the current development status of the optimization applied dynamically in the construction phase and their potential for applying real data collected by ICT. This article reviews 72 relevant optimization methods and identified some of the ICT research studies that can provide them with dynamic data. The dynamic triggering mode of each research is first analyzed, then its dynamic way, dynamic data, data resource, optimization object, and method are identified and formulated. The results reveal the great value of dynamic optimization in dealing with the complicated and uncertain contextual conditions in construction. Different dynamic triggering modes have different affinities with real data. Then, through the analysis of ICT articles, the huge potential of these dynamic optimization methods in applying real data is shown. This paper points out the most practical dynamic mode for engineers or managers to continuously apply optimization methods to solve dynamic problems in construction, and put forward scientific questions for related researchers: How does one combine ICT with the event dynamics or uncertain parameters? Based on this, the research gap of this area is identified a conceptual solution is proposed.

Keywords: optimization; construction; information and communication technology (ICT); scheduling; construction planning; building information modelling (BIM)

\section{Introduction}

The construction industry occupies a large proportion of the national economy and has gathered many human, material, and financial resources. The challenges are faced by construction engineering and management as increasing construction scales and everchanging construction environments have increased the complexity and process dynamics of construction activities and projects [1]. The optimization in the construction or related operation is vital to minimize project cost and duration [2], as it helps to reduce the total cost while increasing $\mathrm{CO}_{2}$ emission negligibly [3].

However, it is almost impossible to carry out the project as is optimized; even good initial calculations could generate an error of $14 \%$ when implementing [4]. The construction project's success and achieving those objectives are affected by risk. It is very important to consider various risk factors before implementing, which makes construction projects more sustainable [5]. However, little work has been carried out on optimizing a complex project where the number of available human operators, construction sites, or material is dynamic [6].

Moreover, with the necessary hardware, sensing equipment and wireless networks are maturing and becoming cheaper, and Internet of Things and computer vision technologies can be widely used in construction [7]. The collected data can also be used to train the artificial intelligence model for delay problem prediction [8]. 
The construction sites can become more intelligent and integrated [9]. The location and status of a truck mixer are collected and transmitted via wireless communications networks in [10], the real-time running states of equipment are identified in [11], the real-time locations of workers are tracked in [12]. The application of information communication technologies (ICT) in construction is moving towards the critical goals of smart construction [13]. Their combination with BIM can improve the performance of construction greatly [14]. However, those applications were mostly about prediction and control, lacking the optimization of the construction process.

The purpose of this article is to study the current development status of the optimization applied dynamically in the construction and their potential of applying real data collected by ICT. This paper defines the concept of optimization applied dynamically in the construction for the first time. This novel perspective encompasses multiple optimization topics such as scheduling, site layout planning, and resource leveling, and classifies them into four dynamic trigger modes. Events dynamics: optimize dynamically to respond to events; periodic mode: optimize with the periodic updating of construction states; relationship dynamics: optimize the problem with uncertain relationships or logics; and uncertain parameter: optimize the problem contains uncertain parameters. It highlights the dynamics of optimization methods in construction and the dynamic data they require, providing strong support for analyzing whether they can be combined with ICT technology. Then, the comparison of different dynamic modes is conducted, which helps engineers or managers understand that the periodic mode is the most practical dynamic mode to continuously apply optimization methods to solve dynamic problems in construction, and put forward scientific questions for related researchers: How does one combine ICT with the event dynamics or uncertain parameters?

The remainder of the paper will first implement a review approach presented by [15], then the reviewed articles are classified into four categories according to their dynamic modes, and in each category, articles are thoroughly reviewed in their dynamic way, dynamic data, data resource, optimization object, and method, and their potential of applying ICT on dynamic data obtainment. Then, the research gap of this area is identified and a conceptual solution is proposed based on it. Lastly, the conclusion is drawn.

\section{Review Method}

To conduct a rigorous review, the approach presented in the research of [15] is implemented. Five main stages that are completed iteratively provide a means to execute a rigorous review of the literature (Figure 1).

Define: The specific topic of the review is identified: that the optimization applied dynamically during construction. According to this, the keywords and searching code of the target articles are determined.

Search: At the initial searching process, 151 articles are identified.

Select: The irrelevant and duplicates papers were eliminated by reading through articles' abstracts, highlights and key scope. This screening process reduced the article number to 72 .

Analyze: Next, the paper's analysis of the 72 articles is based on the following questions:

(1) How the optimization method realizes dynamics;

(2) What data drive its dynamics;

(3) Whether these data can be collected by ICT. 


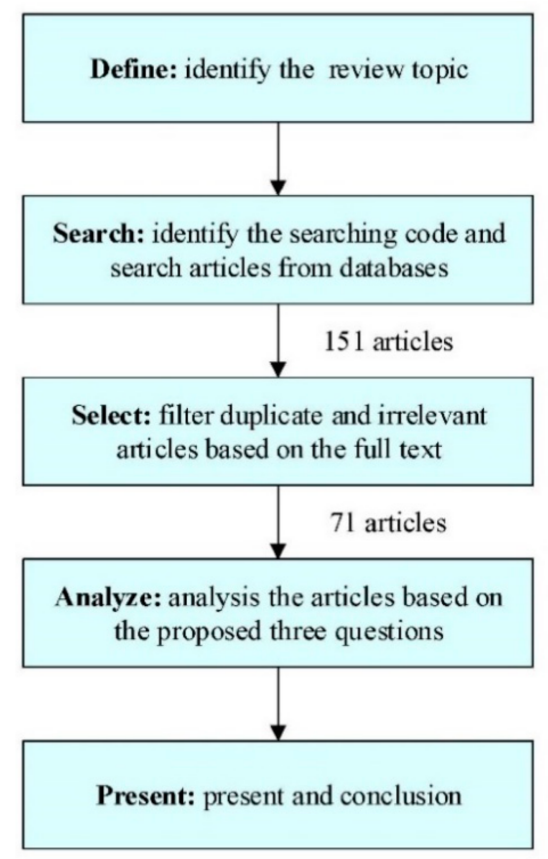

Figure 1. Review strategy followed the five stages in Wolfswinkel et al., 2013.

To the first question, this paper summarizes four dynamic patterns for construction optimization: events dynamics, periodic mode, relationship dynamics, and uncertain parameters. Moreover, to investigate the dynamic contribution of optimization methods and their potential in applying ICT, each study will be comprehensively reviewed to check the dynamic way, dynamic data, data resource, optimization object, and method (whether the ICT is applied). Finally, the potential of dynamic data obtained by ICT is analyzed to solve the third question.

Present: The articles are classified and the number of each category is shown in Figure 2. In each category, the findings of the reviews are presented and summarized in tables (Tables 1-4).



Figure 2. The overall brief of the reviewed articles.

\section{Event Mode}

The events mode is used to optimize dynamically to respond to events, and there are three dynamic ways in this dynamic mode. 


\subsection{Rescheduling}

Various events and uncertainties in construction always make the early prediction deviate from the reality in the construction process. To cope with unexpected events, researchers have proposed the rescheduling defined as a regular deterministic scheduling method [16] that repeatedly invokes the optimization method to optimize the remaining schedule according to the system status after events.

In off-site construction, event-driven rescheduling combines with the GA (Genetic Algorithm) optimization, PSO (particle swarm optimization), EO (evolutionary optimization) could minimize the finish time of the component, maximize the machine load with events happening [17-19]. It also can split the optimization process and evaluation process to build a two-level rescheduling model to consider the different production lines selection in prefabricates production [20]. In construction schedule optimization, event-driven rescheduling policy combines with mathematic optimization, constraint programming $(\mathrm{CP})$ can dynamically minimize the project cost and [21,22]. Similar to the rescheduling policy, Liu et al. proposed a dynamic emergency handling mechanism to handle dynamic events, such as inserting new parts, in construction schedule optimization [23]. By considering both on-site and off-site risks, Chen et al. proposed a dynamic scheduling model based on simulated annealing (SA), which attempts to address delay risks using the collaboration of on-site and off-site project activities [24].

\subsection{Adapt Algorithm}

On the other side, studies directly adapt the optimization method to deal with unexpected events in the construction process. In these, the events directly affect the constraints and encoding states of the algorithm that the optimization can respond to specific events in real-time and make the optimal solution according to the current situation [6]. In specific, the crossover and mutation can be used to express events such as the change of assembly order and the number of workers. Similarly, Wen et al. improved the variable neighborhood search algorithm (VNSA) by the insertion of random jobs and machine failure [25]. Wang et al. improved GA in crossover and mutation operations to achieve the dynamic adjustment of the assembly sequence [26].

\subsection{Event Accepted by Agents}

Researchers have also integrated the optimization method with discrete event simulation (DES) or multiagent system to deal with events. Du et al. develop a dynamic decision support framework based on GA and a multiagent system to simulate and optimize production scheduling [27]. In these, the agents can accept the randomly triggered events, such as machine failure, and then affect the system status, that is, the reduction of machine amount (which is the constraint of GA) (Figure 3). Similarly, Cheng and Tran used DES to considered uncertainties and unexpected events such as truck breakdowns, and a chaotic initialized opposition multi-objective differential evolution algorithm (EA) is used to optimize the truck dispatching schedule [28].



Figure 3. The part of the agent system to deal with events. Reprinted with permission from [27]. Copyright 2021 John Wiley \& Sons. 


\subsection{Conclusion and the Potential to Combine ICT Technology and Apply Real Data}

The dynamic way, dynamic data, data resource, optimization object, and method of reviewed articles in "event mode" are summarized in Table 1. It can be seen that there are six optimization algorithms applied. Most of the optimization algorithms are heuristic or metaheuristic algorithms, like GA, PSO, and ACO (Ant Colony Optimization). Such algorithms generally follow four steps in solving the problem:

(1) The algorithm begins with several potential solutions that encoded according to the current optimization object;

(2) Then they are substituted into the "fitness function" to calculate which of them is relatively optimal;

(3) The optimal ones are more likely to be taken as the blueprints to generate the new solutions, different optimization algorithm has a different way to generate new solutions like that GA generates new individuals by mimicking the mutation and crossover of genes;

(4) Repeat step 2, iterate until the extremum or achievement of optimization goal.

Any solution must satisfy the given constraints. Other optimization algorithms, such as linear programming (LP) and constraint programming (CP), have similar parts.

Table 1. The dynamic data, data resource, optimization topic, and algorithm of event mode.

\begin{tabular}{|c|c|c|c|c|}
\hline Article & Dynamic Data & Dynamic Data Resource & Optimization Topic & Algorithm \\
\hline \multicolumn{5}{|c|}{ Rescheduling } \\
\hline [17] & orders change, machine failures & randomly trigger & production scheduling & GA \\
\hline [18] & orders change, machine failures & randomly trigger & production scheduling & PSO \\
\hline [19] & machine failures, newly jobs & randomly trigger & production scheduling & $\mathrm{EO}$ \\
\hline [20] & demand change of PCs & pre-scheduled & production scheduling & GA \\
\hline [21] & material delays & pre-scheduled & construction scheduling & $\mathrm{CP}$ \\
\hline [22] & productivity modification & pre-scheduled & construction scheduling & $\mathrm{CP}$ \\
\hline [23] & job insertion & pre-scheduled & construction scheduling & $\mathrm{ACO}$ \\
\hline [24] & machine failures, production delay & pre-scheduled & construction scheduling & SA \\
\hline \multicolumn{5}{|c|}{ Adapt algorithm } \\
\hline [6] & order and workers change & randomly trigger & construction scheduling & GA \\
\hline [25] & machine failure and job insertion & randomly triggered & construction scheduling & VNSA \\
\hline [26] & assembly sequence change & randomly trigger & construction scheduling & GA \\
\hline \multicolumn{5}{|c|}{ Event accepted by agents } \\
\hline [27] & machine failures, resource change & randomly trigger & production scheduling & GA \\
\hline [28] & truck breakdowns & randomly trigger & equipment scheduling & EA \\
\hline
\end{tabular}

The introduction of events affects algorithms in many aspects. The order change affects its initial encoding status, the machine failure affects its constraints, and the productivity modification affects its result of the fitness function. "Rescheduling", "Adapt algorithm" and "Event accepted by agents" are three dynamic ways that are differentiated in "event mode" according to the way they handle events. The rescheduling way repeatedly invokes the optimization method after events, it is the most applied way in event mode while each rescheduling process costs much calculation and time. The "adapt algorithm" way directly affects the constraints and encoding states of the algorithm that the randomly happened events can be responded to in real-time, while it is difficult to react to a certain event that is not defined in the algorithm. The "agent-based" way can accept the randomly triggered events and then affect the system status. In fact, the agent can be taken as the event acceptance interference to responded to the real happened events.

Whether the events can be successfully monitored during the construction process is vital to whether the optimization method can be continuously and dynamically applied in engineering practice. The reviewed articles in "event mode" rarely use real-time events to 
verify their algorithms. In this example, events are triggered randomly $[17,18]$ or according to a prepared event schedule [20], and affect the algorithm directly, without considering the detection and identification of events. Additionally, the effect of event duration is not considered in the current dynamic optimization methods. When an occupation event occurs, such as mechanical failure, it changes the system's status and can be reflected in algorithm constraints. However, the end of such an event also changes the system's status back.

The unexpected events, such as material delays and equipment failures, need to be correctly identified and reported in time. With the help of ICT, events in construction can be monitored and captured in many ways. Like this, the real-time mechanical operating state can be identified by learning its operating images [11] or using active sensors such as accelerometers and gyroscopes of machines to monitor its operation status [29]. The sound recognition could also help identify the current construction events that provide dynamic data of process change [30]. The dynamic data of material delays can be obtained from RFID (radio frequency identification) and the Global Position System [31]. The dynamic data of equipment or workers change in $[6,22]$ can be obtained from video images $[32,33]$.

\section{Periodic Mode}

The periodic mode is used to optimize with the periodic updating of construction states, and there are three periodic ways in this dynamic mode.

\subsection{Dynamic Construction Site Layout Planning Problem}

At the different stages of construction, site facilities and site space are termed as dynamic. Optimizing site layouts in multiple stags is defined as dynamic construction site layout planning (DCSLP). Most of the optimization algorithms are heuristic, and Farmakis and Chassiakos applied GA on the multi-objective optimization of DCSLP [34]. Hawarneh et al. consider dynamic facilities planning in multiple construction stages [35]. In [36], the security planning is also considered. Research also adopted a simulated annealing algorithm in DCSLP [37], and BIM could be used to automate the information importation at construction phase intervals [38]. The continuous dynamic searching scheme can be used to guide heuristic algorithms, such as the max-min ant system (MMAS) and Pareto-based ant colony to solve DCSLP [39,40]. In [41], the genetic algorithms (GA) are integrated with a robust search objective to optimize the facility relocation. Moreover, through a continuous dynamic searching scheme and levy flights algorithm (LFA), the plans of multiple construction phases can be optimized as a single plan [42]. Similarly, Andayesh and Sadeghpour applied the minimum energy principles (MEP) to optimize the dynamic site layout plan that allows the simultaneous optimization of facilities in different stages [43].

The mathematical optimization algorithm, dynamic programming (DP), could help to estimate the future effects of layout decisions in the early stages [44]. To compare the difference between the heuristic algorithm and mathematical algorithm in solving DCSLP, Said and El-Rayes present and compare GA and Approximate Dynamic Programming (ADP) [45]. It was found that ADP outperformed GA in terms of effectiveness and efficiency, but GA still proves to be a viable optimization tool because of its simplicity and multiobjective optimization capabilities. As for the material transportation or supply planning in differents, Lan and Xia combine the material planning with construction process simulation to dynamically optimize material transportation at different stages [46]. Zhang and $\mathrm{Yu}$ address the dynamic interaction and coordination among the multiple stages to solve the dynamic transportation planning problem [47]. Fattahi et al. considered the uncertain demand distribution and stochastic facilities' availability [48].

Little research in DCSLP has applied ICT technology. Jiang et al. collected real-time 3D spatial information using an unmanned aerial vehicle for 3D reconstruction of facilities in DCSLP, which greatly improved planning efficiency and reliability [49]. 


\subsection{Dynamic Material and Temporary Facility Layout Problem}

At one certain construction stage, due to the dynamic entertainments, location and operation of site objects, there are still a lot of dynamic factors in sites [43]. Thus, it needs to dynamically optimize the layouts or locations of materials or equipment during the construction stage.

The material placement can be optimized dynamically by using heuristic algorithms like [50]. With the help of the simulation of arrival and consumption of materials, the optimization of material layouts can be more efficient and prospective [51]. The GNSS (global navigation satellite system) and the RFID technology can help to trace the position of materials. In their study, Liu, et al. [31], by using GNSS and RFID, predicted the supply of materials within two days, and the storage state was updated every two hours-a short period according to the construction schedule and arrival sequence. Li et al. adopted an imaging technology with a low-rank matrix to identify on-site unoccupied locations automatically in real-time (Figure 4) to determine the real-time space availability, which would update the hard constraints of GA and then reoptimize the site layouts [52]. Moreover, Chen and Adey considered the factors of material consumption, and applied imaging technology to recognize the current construction status [53]. In this, the BIM played a key role in integrating the relevant information. Liu et al. also adopted BIM to calculate the quantity demanded in the near future for dynamic material layout optimization [31].

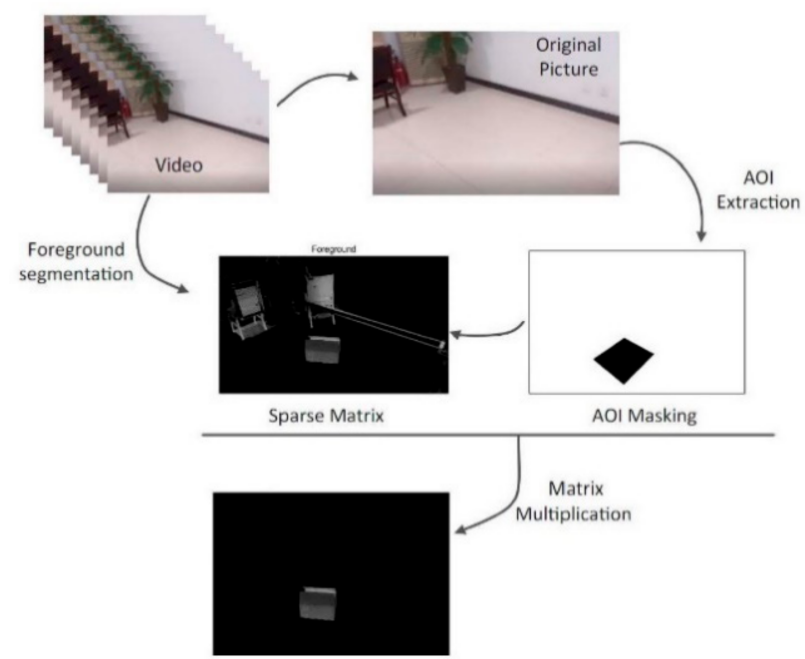

Figure 4. The occupation states identification at the area of interest (AOI). Reprinted with permission from [52]. Copyright 2021 Elsevier.

\subsection{Other Periodic Updates for Dynamics}

Apart from the optimization of site layouts, optimization applied periodically can also be used to solve dynamic equipment allocation [54], task scheduling [55] and rescheduling [56]. The constraint can also be dynamic in schedule optimization [57]. Abuwarda and Hegazy proposed a flexible constraint programming framework to deal with the evolving project constraints in schedule optimization [58]. Zhang et al. realized the real-time dynamic scheduling optimization under the dynamic change of construction resources [59].

Correia and Parente applied information and communication technologies for equipment productivity monitors, and realize dynamic optimization of equipment allocation through periodic updating of productivity [60]. In [10], the current location and status of a truck mixer are collected and transmitted via wireless communications networks, enabling periodically simulation-based optimization (SBO) of the production schedule and truck fleet configuration. 


\subsection{Conclusion and the Potential to Combine ICT}

The summary of the periodic mode is shown in Table 2. It shows that there are six kinds of optimization algorithms are applied, and the heuristic algorithm, like GA, is the most applied. The periodic mode has an impact on various aspects of the optimization algorithm, like the encoding status change with system status updates, the constraints change with available space and resource update, and the result of the fitness function changes as well.

Table 2. The dynamic data, data resource, optimization topic, and algorithm of periodic mode.

\begin{tabular}{|c|c|c|c|c|}
\hline & Dynamic Data & Dynamic Data Resource & Optimization Topic & Algorithm \\
\hline \multicolumn{5}{|c|}{ Dynamic Construction Site Layout Planning Problem } \\
\hline [39] & site status & project documents & DCSLP & MMAS \\
\hline [40] & site status & project documents & DCSLP & $\mathrm{ACO}$ \\
\hline [34] & site status & project documents & DCSLP & GA \\
\hline [35] & facilities' demand & project documents & facilities planning & LP \\
\hline [36] & site status & project documents & DCSLP & PSO \\
\hline [41] & dynamic site status & project documents & facility relocation & GA \\
\hline [37] & dynamic site status & project documents & tower crane planning & SA \\
\hline [38] & dynamic facilities' demand & BIM model & DCSLP & GA \\
\hline [44] & dynamic site status & project documents & DCSLP & DP \\
\hline [45] & dynamic site status & project documents & DCSLP & GA/ADP \\
\hline [42] & dynamic site status & project documents & DCSLP & LFA \\
\hline [43] & dynamic site status & project documents & DCSLP & MEP \\
\hline [47] & dynamic site status & project documents & transportation planning & PSO \\
\hline [48] & dynamic material's demand & project documents & material supply chain & stochastic programs \\
\hline [46] & dynamic material's demand & project documents & transportation planning & mathematic method \\
\hline [49] & dynamic site status & unmanned aerial vehicle & DCSLP & LP \\
\hline \multicolumn{5}{|c|}{ Dynamic material and temporary facility layout problem } \\
\hline [50] & arrival/departure of material & project records & material inventory & GA \\
\hline [51] & incoming/outgoing materials & Predetermined & material inventory & GA \\
\hline [31] & arriving time, type, quantity of material & GNSS and RFID & material inventory & GA \\
\hline [52] & material supply, yard availability & imaging technology & material inventory & GA \\
\hline [53] & material supply and demand & imaging technology, BIM & material inventory & EA \\
\hline \multicolumn{5}{|c|}{ Other periodic updates for dynamics } \\
\hline [54] & equipment failures & project records & equipment allocation & PSO \\
\hline [55] & drop, rise of water level & project records & construction dewatering & mathematic method \\
\hline [56] & dynamic construction process & project documents & schedule optimization & GA \\
\hline [58] & evolving project constraints & prescheduled & construction Scheduling & $\mathrm{CP}$ \\
\hline [57] & dynamic constraints & project documents & schedule optimization & GA \\
\hline [59] & change of resource & project documents & schedule optimization & mathematic method \\
\hline$[60]$ & equipment productivity & GPS-sensors & equipment allocation & GA \\
\hline [10] & location and status of equipment & data sensor & equipment allocation & SBO \\
\hline
\end{tabular}

According to the periodic way and optimization topics, the article in periodic mode can be subdivide into "Dynamic construction site layout planning problem (DCSLP)", "Dynamic material and temporary facility layout problem" and "Other periodic updates for dynamics" three kinds. There is information that, 1 of the 16 DCSLP, 3 of the 5 facilities or material layout research, 2 of 8 other research studies applied ICT technology to obtain the required dynamic data. In DCSLP, even though ICT technology has shown great advantages and value in obtaining dynamic data [49], few studies have applied it. Because there is much time between two-stage intervals and the relevant engineering documents are enough to offer necessary data. While the dynamic material and facility layout problem requires more frequent information updates. Table 2 shows that the dynamic data used in this kind of dynamic optimization are the material schedule, the occupation status of the site, and the current construction progress. Some research used RFID and GNSS technology 
to obtain or estimate the arrival time of materials [31], imaging technology to identify the occupation status of the site [52], GPS-sensors and laser scan for productivity analysis [60]. By using relevant ICT technologies, these studies can efficiently obtain a large amount of real data and update the corresponding system status to influence the optimization algorithm. Which makes dynamic optimization more practical during construction.

Moreover, many other ICT-related studies can provide dynamic data to periodic mode. Through the recognition of workers' action [61], construction equipment action [62], or the monitoring of the hoisting status of the precast wall [63], the current construction process can be determined. By extracting both temporal and spatial information of the equipment from a long video, the current productivity can be analyzed [64,65]. Through analyzing various types of $2 \mathrm{D}$ and $3 \mathrm{D}$ sensory data, the earthmoving equipment state can be identified in [66]. The current site status can be identified by detecting the construction workforce and equipment status in high definition video [67].

\section{Uncertain Relationships}

The uncertain relationships mode is used to optimize the problem with uncertain relationships or logics, such as the dynamic connections between tasks and resources. In the construction scheduling problem, DES is good at describing relationship dynamics that Zhang and Li utilized to simulate dynamic resource allocation problems in construction scheduling [68]. Similarly, Khodabandelu et al. developed agent-based modelling to simulate the dynamic linkage between tasks, cranes, and supply locations [69].

In the site layout planning problem, Sonmez and Gurel used GA-based dynamic selection of resource utilization to optimize planning and scheduling of large-scale construction projects [70]. Xu et al. applied fuzzy logic to represent the closeness relationship between temporary facilities [71]. As regards other problems, dynamic resource sharing is also applied in the off-site construction process to realize the dynamic of the optimization method [72]. Gu et al. integrate spatial block modelling and location meshing to simulate the uncertain routes and dynamic loading points to solve the construction-materials stationary plant site-selection problem [73].

In the uncertain relationship mode, dynamics are realized through uncertain relationships of elements, such as dynamic resource sharing [68], dynamic loading points of the material in [70]. Heuristic or meta-heuristic methods can be used to compare the optimization results under different relationships to select the optimal relationship pattern (resource allocation relationship, material drop relationship, etc.). This form of dynamic is pre-determined (see Table 3) when the model is established, so it has little potential to use the real data during construction continually.

Table 3. The dynamic data, data resource, optimization topic, and algorithm of uncertain relationships.

\begin{tabular}{ccccc}
\hline Article & Dynamic Data & Dynamic Data Resource & Optimization Topic & Algorithm \\
\hline$[68]$ & dynamic linkage between tasks, cranes, and supply locations & predetermined & layout optimization & PSO \\
{$[69]$} & dynamics of resource sharing & production data & layout optimization & metaheuristics \\
{$[70]$} & uncertain routes and loading points & predetermined & material supply chain & GA \\
{$[71]$} & multiple duration/resource execution modes & predetermined & planning and scheduling & GA \\
{$[72]$} & fuzzy logic between facilities & predetermined & facilities planning & GA \\
{$[73]$} & dynamic resource allocation & predetermined & Project scheduling & heuristic \\
\hline
\end{tabular}

\section{Uncertain Parameter}

The uncertain parameter is used to optimize the problem containing uncertain parameters like weather conditions, personnel efficiency and task duration, and so on. It can be subdivided into the following kinds: probabilistic distribution, mathematic model and fuzzy theory. 


\subsection{Probabilistic Distribution}

The most widely used uncertain parameter is the floating time of the task. This technique can be traced back to earlier studies in job-shop scheduling. In stochastic project scheduling problem, it is expressed as the probability distributions of task duration, like the triangular distribution in [74], the random variables in [75]. In [76], by shifting non-critical activities within their forward free float, forward, total float, and backward free float, the schedule duration and resource allocation may be optimized. The uncertainties of module delivery time and equipment breakdowns can be expressed as dynamic parameters as well [77]. Similarly, Hassan et al. considered uncertainty in crew production rates [78].

Researchers also use agents to simulate the probability distribution of task duration in DES so that the DES model can provide the simulation result to evaluate the possible solutions [74]. Nadoushani et al. considered the ratio of idle to non-idle emission rates of equipment in DES [79]. Wang et al. used the DES-GA hybrid method to simulate the triangular distribution of processing time and optimize the on-time delivery of precast components [80]. Cheng and Chang considered the dynamic factors of schedule changes, material delays, storage location changes, and task floating time [81]. This means it includes three dynamic ways in optimization: reacting to events, updating status periodically and parameter (task) uncertainty.

\subsection{Mathematic Model}

Another way is to use the mathematical model to describe the dynamic change of parameters. He et al. fit the relationship between duration and cost into a linear or nonlinear function and applied it in the GA optimization algorithm [82]. In [83], a "maturity" model is proposed to quantify the changes that affecting the task's duration. Ke and Liu integrate stochastic simulation with genetic algorithm to solve three types of stochastic models: the expected cost model, the $\alpha$-cost model, and the probability maximization model [84]. Roofigari-Esfahan and Razavi built uncertainties upon the new concept of space-time float [85]. In [86], the uncertainty factors such as interest rates and prices are expressed by establishing quality, cost and schedule function. Abuwarda and Hegazy considered the uncertainty in geologic conditions as geologic parameters [58]. Zhou and Ma applied dynamic weighting methods to describe the relationship between time, cost, quality and resources [87]. Abotaleb et al. mimicked the "dynamic" geometries of site facilities for modelling regular and irregular freeform shapes of site facilities in DCSLP (Figure 5) [88]. If a facility (object) is outside the site boundaries in any of the shapes, the constraint will result in a penalty added to the objective function of the optimization algorithm. Huang et al. improved the PSO by integrating niche technology and using dynamic inertia weight in it [89].

a

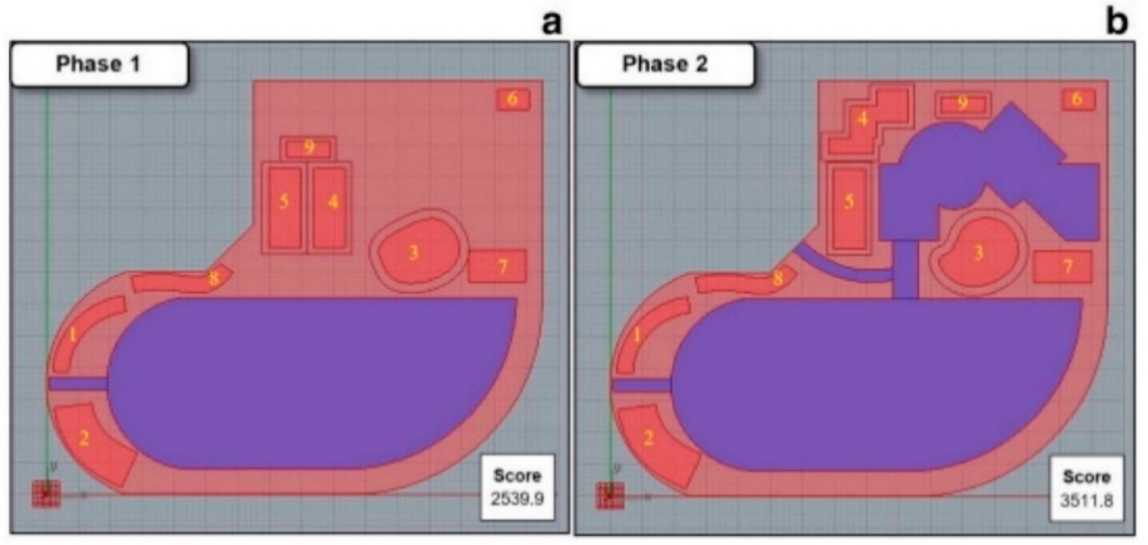

Figure 5. The dynamic geometries of site facilities in dynamic construction site layout planning of phase 1 (a) and phase 2 (b) (Blocks with a number are facilities, the darker block is building). Reprinted with permission from [88]. Copyright 2021 Elsevier. 


\subsection{Fuzzy Theory}

The fuzzy theory can be used to describe uncertainty. In [90], the linear programming is elaborated, allowing for the inputs in the form of fuzzy numbers for material supply channels optimization. Bakry et al. use fuzzy set theory for modelling uncertainties and then optimize the repetitive construction project schedule [91]. In [92], the uncertainties associated with the crew productivity rate and quantity of work are expressed by fuzzy set theory. In [93], fuzzy sets are used to consider the effects of time and cost uncertainties on construction works. Pan proposed a fuzzy inference-based optimization mechanism to better input the fuzzy number into the optimization algorithm [94].

The fuzzy theory also combines with periodic mode. Xu et al. used fuzzy variables to express equipment failures in solving multistage construction equipment allocation problems [95]. In [96], the interaction cost and the operating cost of facilities in DCSLPP are regarded as fuzzy random variables, and similarly in [97]. Those research studies contain both parameter uncertainty and periodic updating dynamics.

\subsection{Conclusion and the Potential to Combine ICT}

The summary of the uncertain parameter is shown in Table 4, displaying that eight kinds of optimization algorithms show up in this mode, and the GA algorithm is still the most widely used optimization method, then PSO algorithm. Uncertainty parameters are mainly expressed in three ways: Probabilistic distribution, mathematical model and fuzzy theory. Probabilistic distribution describes the various possible values and the probability of the parameter in the future. While the mathematical model is more inclined to estimate the future characteristics of the parameters, and it depends more on the accurate estimation given in the early stage. The fuzzy theory allows the input of fuzzy parameters, which is more suitable for situations where the characteristics of construction data are insufficient.

The uncertainty parameter established based on the probability distribution, mathematical model and fuzzy theory can take the dynamic factors into the optimization. Although the dynamics in the parameter are a priori, the real on-site data can help revise the probability distribution or mathematical model in the short-term future, making the parameter dynamic optimization method more realistic. Examples of this can be found in the dynamically adjusted mathematical model for real-time control of construction in [98], the activity-level simulation with real-time construction data in [99], the task duration updating by real-time data collected by built-in smartphone sensors in [100], and the Dynamic Bayesian Network model for probabilistic assessment of tunnel construction performance [101]. Moreover, historical data can also help to build a more accurate parameter model. Gelisen and Griffis proposed an automated productivity-based schedule animation that stochastically utilizes weekly trended construction labor productivity data [102]. Srour et al. mined past data to select the most appropriate learning model of task duration [103]. Damnjanovic and Reinschmidt applied Bayesian methods for updating model parameters, such as machine failures, based on new project-specific data [104]. Although these studies are basically construction control and prediction and not optimization, they show the great potential of combing optimization methods with ICT to constantly collect actual construction data to update the uncertain parameters.

Table 4. The dynamic data, data resource, optimization topic, and algorithm of the uncertain parameter.

\begin{tabular}{lccc}
\hline & Dynamic Data & Dynamic Data Resource & Optimization Topic \\
\hline & & Probabilistic distribution & \\
\hline$[77]$ & material delay, equipment failures & known distribution & project scheduling \\
{$[75]$} & activity durations & known distribution & project scheduling \\
{$[76]$} & activity durations & known distribution & project scheduling \\
{$[78]$} & crew production rates & known distribution & project scheduling \\
{$[74]$} & activity duration, weather condition & randomly trigger & project scheduling \\
{$[79]$} & idle rates of equipment, activity duration & known distribution & concrete placing scheduling \\
{$[80]$} & triangular distribution of activity durations & known distribution & project scheduling \\
{$[81]$} & task floating time & known distribution & material layout \\
\hline
\end{tabular}


Table 4. Cont.

\begin{tabular}{|c|c|c|c|c|}
\hline & Dynamic Data & Dynamic Data Resource & Optimization Topic & Algorithm \\
\hline \multicolumn{5}{|c|}{ Mathematic model } \\
\hline [82] & duration and cost & predetermined & project scheduling & GA \\
\hline [83] & task duration & predetermined & project scheduling & SBO \\
\hline [84] & cost-time function & predetermined & project scheduling & GA \\
\hline [85] & space-time float & predetermined & optimize the duration & $\mathrm{LP}$ \\
\hline [86] & quality, cost and schedule function & predetermined & schedule cost optimization & GA \\
\hline [87] & weights between time, cost, quality and resources & predetermined & project Scheduling & PSO \\
\hline [88] & geometries of facilities & predetermined & facilities layout & GA \\
\hline [89] & resources uncertainties & predetermined & project Scheduling & PSO \\
\hline \multicolumn{5}{|c|}{ Fuzzy theory } \\
\hline [90] & task duration, material supply & predetermined & material supply chain & $\mathrm{LP}$ \\
\hline [91] & work quantities, crews' productivities and costs & predetermined & project Scheduling & GA \\
\hline [92] & crew productivity & predetermined & project Scheduling & GA \\
\hline [93] & time and cost & predetermined & project Scheduling & GA \\
\hline [94] & human bias and uncertainty & predetermined & resource-allocation & SBO \\
\hline [95] & equipment failure rate & predetermined & project Scheduling & DP-based GA \\
\hline [96] & interaction cost and operating cost of facilities & predetermined & project Scheduling & PSO \\
\hline [97] & transportation cost of facilities & predetermined & project Scheduling & DP-based PSO \\
\hline
\end{tabular}

\section{Research Gap Identification}

From the review of the four kinds of dynamic optimization, there are only six articles from the periodic mode that applied ICT technology to obtain the required dynamic data. Although the event mode is the most timely response to changes in construction status compared to other modes, it lacks engineering practicality. It lays on the fact that events in event mode are triggered randomly or according to a prepared event schedule while ignores the detection and identification process of events. Moreover, the effect of event duration is not considered, which significantly impacts the dynamic optimization results. Discrete event simulation may solve this problem. The DES agent can refuse any new tasks when a mechanical failure event occurred, but re-accepted the new tasks after the event. In this way, the system status changed twice on one event, that event duration can be considered.

The periodic mode is the most studied in the reviewed articles ( 29 of 72 articles are periodic mode), and it responds more comprehensively to system state changes when comparing with other modes. Moreover, the periodic mode applied the most ICT technologies that reflect its practicality in engineering. In the "Dynamic material and temporary facility layout problem", the time cost of status updating is greatly shortened with the assistance of ICT technology, and the period can therefore be compressed to about one day (Chen, de Soto and Adey). However, this mode still faces the problems of the difficulties in dealing with construction state changes promptly and the huge computational burden brought by periodic optimization.

The uncertain relationships mode tends to describe the system dynamics once and for all in the early stages. Although it may be more in line with the initial state of the system at the beginning, it is likely to deviate from the actual situation over time and hard to adjust. This way, it has little potential to use the real data during construction continually. The uncertain parameter mode is a priori that similar to the uncertain relationships mode. However, the parameter is replaceable because real on-site data can help revise the probability distribution or mathematical model in the short-term future, making the parameter dynamic optimization method more realistic. The construction control and prediction-related research studies have shown the great potential of combing optimization methods with ICT to constantly collect actual construction data to update the uncertain parameters. On the other hand, more engineering practices on uncertain parameters updated by on-site data are needed.

Whether the optimization method can monitor and respond to the real-time event or construction status is the key to whether it can be constantly and dynamically applied 
in engineering practice. Researchers have applied ICT to monitor and report various construction events such as material delays (Liu, et al., 2020) and equipment failures (Cheng, et al., 2017), collection of real data for probability distribution estimating (Spackova and Straub 2013). Thus, the current dynamic optimization methods need to integrate with ICT to respond to events and change system status, or to re-evaluate the dynamic parameters. DES may help to realize this for the following reasons: DES's agent can respond to the event to change the state and return to the original state after the end of the event; the agent provides an interface for dynamic data importation; the agent can express the uncertainty of the parameter model or probability distribution. Moreover, BIM can be used to integrate ICT, DES simulation model, and heuristic optimization.

\section{Conclusions}

This paper reviews 72 optimization methods that are applied dynamically during construction. It summarizes four dynamic modes: event mode, periodic mode, relationship dynamics and uncertain parameter. Through the entire reading of these dynamic optimization studies, this paper analyzes the dynamic data of each research and their sources, and the impact of dynamic data on optimization methods. Reviewing relevant ICT articles based on the required dynamic data shows that different dynamic modes have different potentials for applying ICT. The following conclusions can be drawn:

(1) Dynamic data of the event mode are mainly about the events that affect the encoding status, constraints and results of fitness function of optimization algorithms. The rescheduling (event-driven), adapt algorithm, and event accepted by agents are three ways adopted to deal with events. However, their data sources are mainly from the default event schedule and random triggering that lacking the application of real-time events. So far, ICT can monitor and identify the events in real-time, which means that they have the great potential to be combined with dynamic optimization.

(2) In the periodic mode, the optimization method is applied periodically with the system status update. Research has proven the huge application value of ICT in DCSLP. As for the dynamic material and facility layout problem, more ICT such as RFID, imaging techniques are applied to identify the current status of the site, which makes dynamic optimization have more practical significance in construction and reflects the great application value of ICT technology in dynamic optimization.

(3) The uncertain relationship dynamics are pre-determined when the model is established, so it is not easy to use the real data continually during construction. Uncertain parameter brings dynamics into optimization by a probability distribution, fuzzy theory and mathematic model. This form of dynamics is more forward-looking than events and periodic mode. Although almost no ICT technology is used in this type of optimization, the uncertain parameter can be updated during construction by using real construction data in process control and prediction studies, etc., which shows the great application potential of ICT in it.

The main contribution of this paper is to point out the ways of applied optimization methods dynamically in the digital construction site for the future. When faced with constant monitoring of real-time data, an optimization method can be dynamically applied in at least three ways. The most mature dynamic method is to periodically update the construction status and repeatedly invoke the optimization method. It is still necessary to pay attention to the time-consuming problem when applying the optimization method periodically, and some unchanged states can reduce the workload. The second mature method is to apply the uncertain parameter predicated through actual data in the optimization method, while there is still need a case to apply ICT technology in this type of optimization. As for the event mode, although it has some difficulties in practical application, when there are significant events that happen in the construction, it is the timeliest method to respond to it. Thus, it is urgent to study how ICT can be applied in the event mode. Two problems need to be solved: ICT could monitor and recognize the events, but how can the recognized events be reported and affect the optimization system, and how does one take the event 
duration into account? This article concludes that the combination of DES, ICT and BIM may solve these two problems.

By reading this article, relevant engineers or managers can learn at least three ways to apply optimization methods continuously in construction and solve dynamic construction problems, and by reading the combination degree of dynamic optimization methods and ICT, they can understand which way is more suitable for practical engineering. It can also encourage relevant researchers to combine the event mode and uncertain parameter mode with ICT technology, as the event mode especially can provide an immediate response to unexpected events.

Author Contributions: Formal analysis, B.Z.; investigation, J.X.; writing—original draft preparation, Z.W.; supervision, B.Y.; project administration, B.L.; funding acquisition, D.Z.; verification, M.D. All authors have read and agreed to the published version of the manuscript.

Funding: This research received no external funding.

Data Availability Statement: Not applicable.

Conflicts of Interest: The authors declare no conflict of interest.

$\begin{array}{ll}\text { Abbreviations } \\ \text { ACO } & \text { Ant Colony Optimization } \\ \text { ADP } & \text { Approximate Dynamic Programming } \\ \text { BIM } & \text { Building Information Modelling } \\ \text { CP } & \text { Constraint Programming } \\ \text { DCSLP } & \text { Dynamic Construction Site Layout Planning } \\ \text { DES } & \text { Discrete Event Simulation } \\ \text { DP } & \text { Dynamic Programming } \\ \text { EA } & \text { Evolution Algorithm } \\ \text { EO } & \text { Evolutionary Optimization } \\ \text { GA } & \text { Genetic Algorithm } \\ \text { GNSS } & \text { Global Navigation Satellite System } \\ \text { ICT } & \text { Information and Communication Technologies } \\ \text { LFA } & \text { Levy Flights Algorithm } \\ \text { LP } & \text { Linear Programming } \\ \text { MEP } & \text { Minimum Energy Principles } \\ \text { MMAS } & \text { Max-min Ant System } \\ \text { PSO } & \text { Particle Swarm Optimization } \\ \text { SA } & \text { Simulated Annealing } \\ \text { SBO } & \text { Simulation-based Optimization } \\ \text { VNSA } & \text { Variable Neighborhood Search Algorithm } \\ & \end{array}$

\section{References}

1. Ding, Z.; Zuo, J.; Wu, J.; Wang, J. Key factors for the BIM adoption by architects: A China study. Eng. Constr. Arch. Manag. 2015, 22, 732-748. [CrossRef]

2. Choi, J.; Xuelei, J.; Jeong, W. Optimizing the Construction Job Site Vehicle Scheduling Problem. Sustainability 2018, 10, 1381. [CrossRef]

3. An, H.; Byon, Y.-J.; Cho, C.-S. Economic and Environmental Evaluation of a Brick Delivery System Based on Multi-Trip Vehicle Loader Routing Problem for Small Construction Sites. Sustainability 2018, 10, 1427. [CrossRef]

4. Leśniak, A.; Zima, K. Cost Calculation of Construction Projects Including Sustainability Factors Using the Case Based Reasoning (CBR) Method. Sustainability 2018, 10, 1608. [CrossRef]

5. Ghasemi, F.; Sari, M.H.M.; Yousefi, V.; Falsafi, R.; Tamošaitienè, J. Project Portfolio Risk Identification and Analysis, Considering Project Risk Interactions and Using Bayesian Networks. Sustainability 2018, 10, 1609. [CrossRef]

6. Shan, S.; Hu, Z.; Liu, Z.; Shi, J.; Wang, L.; Bi, Z. An adaptive genetic algorithm for demand-driven and resource-constrained project scheduling in aircraft assembly. Inf. Technol. Manag. 2017, 18, 41-53. [CrossRef]

7. Alizadehsalehi, S.; Yitmen, I. A Concept for Automated Construction Progress Monitoring: Technologies Adoption for Benchmarking Project Performance Control. Arab. J. Sci. Eng. 2018, 44, 4993-5008. [CrossRef] 
8. Yaseen, Z.M.; Ali, Z.H.; Salih, S.Q.; Al-Ansari, N. Prediction of Risk Delay in Construction Projects Using a Hybrid Artificial Intelligence Model. Sustainability 2020, 12, 1514. [CrossRef]

9. Sardroud, J.M. Perceptions of automated data collection technology use in the construction industry. J. Civ. Eng. Manag. 2015, 21, 54-66. [CrossRef]

10. Lu, M.; Dai, F.; Chen, W. Real-time decision support for planning concrete plant operations enabled by integrating vehicle tracking technology, simulation, and optimization algorithms. Can. J. Civ. Eng. 2007, 34, 912-922. [CrossRef]

11. Soltani, M.M.; Zhu, Z.; Hammad, A. Skeleton estimation of excavator by detecting its parts. Autom. Constr. 2017, 82, 1-15. [CrossRef]

12. Kim, H.; Han, S. Accuracy Improvement of Real-Time Location Tracking for Construction Workers. Sustainability 2018, 10, 1488 [CrossRef]

13. Jia, M.; Komeily, A.; Wang, Y.; Srinivasan, R.S. Adopting Internet of Things for the development of smart buildings: A review of enabling technologies and applications. Autom. Constr. 2019, 101, 111-126. [CrossRef]

14. Xu, W.; Wang, T.-K. Dynamic safety prewarning mechanism of human-machine-environment using computer vision. Eng. Constr. Arch. Manag. 2020, 27, 1813-1833. [CrossRef]

15. Wolfswinkel, J.F.; Furtmueller-Ettinger, E.; Wilderom, C.P. Using grounded theory as a method for rigorously reviewing literature. Eur. J. Inf. Syst. 2013, 22, 45-55. [CrossRef]

16. Fahmy, A.; Hassan, T.; Bassioni, H.; McCaffer, R. Dynamic scheduling model for the construction industry. Built Environ. Proj. Asset Manag. 2019, 10, 313-330. [CrossRef]

17. Kundakc1, N.; Kulak, O. Hybrid genetic algorithms for minimizing makespan in dynamic job shop scheduling problem. Comput. Ind. Eng. 2016, 96, 31-51. [CrossRef]

18. Li, J.X.; Wen, X.N. Construction and Simulation of Multi-Objective Rescheduling Model Based on PSO. Int. J. Simul. Model. 2020 19, 323-333. [CrossRef]

19. Liu, F.; Wang, S.; Hong, Y.; Yue, X. On the Robust and Stable Flowshop Scheduling Under Stochastic and Dynamic Disruptions. IEEE Trans. Eng. Manag. 2017, 64, 539-553. [CrossRef]

20. Wang, Z.; Hu, H. Dynamic response to demand variability for precast production rescheduling with multiple lines. Int. J. Prod. Res. 2018, 56, 5386-5401. [CrossRef]

21. Liu, J.; Lu, M. Constraint Programming Approach to Optimizing Project Schedules under Material Logistics and Crew Availability Constraints. J. Constr. Eng. Manag. 2018, 144, 04018049. [CrossRef]

22. Liu, S.-S.; Shih, K.-C. Construction rescheduling based on a manufacturing rescheduling framework. Autom. Constr. 2009, 18, 715-723. [CrossRef]

23. Liu, X.; Ni, Z.; Qiu, X. Application of ant colony optimization algorithm in integrated process planning and scheduling. Int. J. Adv. Manuf. Technol. 2016, 84, 393-404. [CrossRef]

24. Chen, W.; Zhao, Y.; Yu, Y.; Chen, K.; Arashpour, M. Collaborative Scheduling of On-Site and Off-Site Operations in Prefabrication. Sustainability 2020, 12, 9266. [CrossRef]

25. Wen, Y.; Xu, H.; Yang, J. A heuristic-based hybrid genetic-variable neighborhood search algorithm for task scheduling in heterogeneous multiprocessor system. Inf. Sci. 2011, 181, 567-581. [CrossRef]

26. Wang, Y.W.; Yuan, Z.M.; Sun, C.S. Research on assembly sequence planning and optimization of precast concrete buildings. J. Civ. Eng. Manag. 2018, 24, 106-115. [CrossRef]

27. Du, J.; Dong, P.; Sugumaran, V.; Castro-Lacouture, D. Dynamic decision support framework for production scheduling using a combined genetic algorithm and multiagent model. Expert Syst. 2021, 38. [CrossRef]

28. Cheng, M.-Y.; Tran, D.-H. Integrating Chaotic Initialized Opposition Multiple-Objective Differential Evolution and Stochastic Simulation to Optimize Ready-Mixed Concrete Truck Dispatch Schedule. J. Manag. Eng. 2016, 32, 04015034. [CrossRef]

29. Cheng, C.-F.; Rashidi, A.; Davenport, M.A.; Anderson, D.V. Activity analysis of construction equipment using audio signals and support vector machines. Autom. Constr. 2017, 81, 240-253. [CrossRef]

30. Cho, C.; Lee, Y.-C.; Zhang, T. Sound Recognition Techniques for Multi-Layered Construction Activities and Events. In Computing in Civil Engineering 2017; American Society of Civil Engineers (ASCE): Reston, VA, USA, 2017; Volume 2017, pp. 326-334.

31. Liu, D.; Li, X.; Chen, J.; Jin, R. Real-Time Optimization of Precast Concrete Component Transportation and Storage. Adv. Civ. Eng. 2020, 2020, 5714910. [CrossRef] [PubMed]

32. Memarzadeh, M.; Golparvar-Fard, M.; Niebles, J.C. Automated 2D detection of construction equipment and workers from site video streams using histograms of oriented gradients and colors. Autom. Constr. 2013, 32, 24-37. [CrossRef]

33. Tajeen, $\mathrm{H} . ; \mathrm{Zhu}, \mathrm{Z}$. Image dataset development for measuring construction equipment recognition performance. Autom. Constr. 2014, 48, 1-10. [CrossRef]

34. Farmakis, P.M.; Chassiakos, A.P. Genetic algorithm optimization for dynamic construction site layout planning. Organ. Technol. Manag. Constr. Int. J. 2017, 10, 1655-1664. [CrossRef]

35. Al Hawarneh, A.; Bendak, S.; Ghanim, F. Dynamic facilities planning model for large scale construction projects. Autom. Constr. 2019, 98, 72-89. [CrossRef]

36. Li, Z.; Shen, W.; Xu, J.; Lev, B. Bilevel and multi-objective dynamic construction site layout and security planning. Autom. Constr. 2015, 57, 1-16. [CrossRef] 
37. Wu, K.; De Soto, B.G.; Zhang, F. Spatio-temporal planning for tower cranes in construction projects with simulated annealing. Autom. Constr. 2020, 111, 103060. [CrossRef]

38. Kumar, S.S.; Cheng, J.C. A BIM-based automated site layout planning framework for congested construction sites. Autom. Constr. 2015, 59, 24-37. [CrossRef]

39. Ning, X.; Lam, K.-C.; Lam, M.C.-K. Dynamic construction site layout planning using max-min ant system. Autom. Constr. 2010, 19, 55-65. [CrossRef]

40. Ning, X.; Lam, K.-C.; Lam, M.C.-K. A decision-making system for construction site layout planning. Autom. Constr. 2011, 20, 459-473. [CrossRef]

41. Farmakis, P.M.; Chassiakos, A.P. Dynamic multi-objective layout planning of construction sites. Procedia Eng. 2017, 196, 674-681. [CrossRef]

42. Yahya, M.; Saka, M. Construction site layout planning using multi-objective artificial bee colony algorithm with Levy flights. Autom. Constr. 2014, 38, 14-29. [CrossRef]

43. Andayesh, M.; Sadeghpour, F. Dynamic site layout planning through minimization of total potential energy. Autom. Constr. 2013, 31, 92-102. [CrossRef]

44. El-Rayes, K.; Said, H. Dynamic Site Layout Planning Using Approximate Dynamic Programming. J. Comput. Civ. Eng. 2009, 23, 119-127. [CrossRef]

45. Said, H.; El-Rayes, K. Performance of global optimization models for dynamic site layout planning of construction projects. Autom. Constr. 2013, 36, 71-78. [CrossRef]

46. Lan, Y.C.; Xia, G.P. The Application of the Simulation-Based Optimization for the Material Planning in Large-Scale Water Conservancy Projects. 2008. Available online: https://www.researchgate.net/publication/290657736 (accessed on 12 January 2008).

47. Zhang, H.; Yu, L. Dynamic transportation planning for prefabricated component supply chain. Eng. Constr. Arch. Manag. 2020, 27, 2553-2576. [CrossRef]

48. Fattahi, M.; Govindan, K. Data-Driven Rolling Horizon Approach for Dynamic Design of Supply Chain Distribution Networks under Disruption and Demand Uncertainty. Decis. Sci. 2020. [CrossRef]

49. Jiang, W.; Zhou, Y.; Ding, L.; Zhou, C.; Ning, X. UAV-based 3D reconstruction for hoist site mapping and layout planning in petrochemical construction. Autom. Constr. 2020, 113, 103137. [CrossRef]

50. Alanjari, P.; Razavialavi, S.; Abourizk, S.M. A simulation-based approach for material yard laydown planning. Autom. Constr. 2014, 40, 1-8. [CrossRef]

51. Alanjari, P.; Razavialavi, S.; Abourizk, S. Hybrid Genetic Algorithm-Simulation Optimization Method for Proactively Planning Layout of Material Yard Laydown. J. Constr. Eng. Manag. 2015, 141, 06015001. [CrossRef]

52. Li, K.; Luo, H.; Skibniewski, M.J. A non-centralized adaptive method for dynamic planning of construction components storage areas. Adv. Eng. Inform. 2019, 39, 80-94. [CrossRef]

53. Chen, Q.; De Soto, B.G.; Adey, B. Transshipment approach to coordinate materials for a contractor's project portfolio. Int. J. Constr Manag. 2020, 1-12. [CrossRef]

54. Xu, J.; Zeng, Z. Applying Optimal Control Model to Dynamic Equipment Allocation Problem: Case Study of Concrete-Faced Rockfill Dam Construction Project. J. Constr. Eng. Manag. 2011, 137, 536-550. [CrossRef]

55. Shi, C.-H.; Cao, C.-Y.; Lei, M.-F.; Peng, L.-M.; Jiang, J. Optimal design and dynamic control of construction dewatering with the consideration of dewatering process. KSCE J. Civ. Eng. 2017, 21, 1161-1169. [CrossRef]

56. Hegazy, T.; Petzold, K. Genetic Optimization for Dynamic Project Control. J. Constr. Eng. Manag. 2003, 129, 396-404. [CrossRef]

57. Lin, C.W.R.; Hsiau, H.J. A genetic algorithm approach for optimizing chemical towers construction project scheduling with dynamic resources constraints. Int. J. Ind. Eng. Theory Appl. Pract. 2010, 17, 128-141.

58. Abuwarda, Z.; Hegazy, T. Work-Package Planning and Schedule Optimization for Projects with Evolving Constraints. J. Comput. Civ. Eng. 2016, 30, 04016022. [CrossRef]

59. Zhang, S.P.; Qi, S.J.; Chen, X.; Chu, X.J. Study on Theory of Real-Time Dynamic Scheduling Optimization under the Drive of Construction Resource. 2009. Available online: https:/ /d.wanfangdata.com.cn/conference/WFHYXW377268 (accessed on 30 August 2010).

60. Correia, A.G.; Parente, M. Coupled ICT and Dynamic Optimization Tools Toward an Integrated Earthwork Management System. In Proceedings of the GeoShanghai 2018 International Conference: Transportation Geotechnics and Pavement Engineering, Shanghai, China, 27 May 2018; pp. 136-143.

61. Yang, J. Enhancing action recognition of construction workers using data-driven scene parsing. J. Civ. Eng. Manag. 2018, 24, 568-580. [CrossRef]

62. Zhang, J.; Zi, L.; Hou, Y.; Wang, M.; Jiang, W.; Deng, D. A Deep Learning-Based Approach to Enable Action Recognition for Construction Equipment. Adv. Civ. Eng. 2020, 2020, 8812928. [CrossRef]

63. Wang, Z.; Zhang, Q.; Yang, B.; Wu, T.; Lei, K.; Zhang, B.; Fang, T. Vision-Based Framework for Automatic Progress Monitoring of Precast Walls by Using Surveillance Videos during the Construction Phase. J. Comput. Civ. Eng. 2021, 35, 04020056. [CrossRef]

64. Chen, C.; Zhu, Z.; Hammad, A.; Ahmed, W. Vision-Based Excavator Activity Recognition and Productivity Analysis in Construction. In Computing in Civil Engineering 2019; American Society of Civil Engineers (ASCE): Reston, VA, USA, 2019; Volume 2019, pp. 241-248. 
65. Chen, C.; Zhu, Z.; Hammad, A. Automated excavators activity recognition and productivity analysis from construction site surveillance videos. Autom. Constr. 2020, 110, 103045. [CrossRef]

66. Vahdatikhaki, F.; Hammad, A. Framework for near real-time simulation of earthmoving projects using location tracking technologies. Autom. Constr. 2014, 42, 50-67. [CrossRef]

67. Zhu, Z.; Ren, X.; Chen, Z. Integrated detection and tracking of workforce and equipment from construction jobsite videos. Autom. Constr. 2017, 81, 161-171. [CrossRef]

68. Zhang, H.; Li, H. Simulation-based optimization for dynamic resource allocation. Autom. Constr. 2004, 13, 409-420. [CrossRef]

69. Khodabandelu, A.; Park, J.; Arteaga, C. Crane operation planning in overlapping areas through dynamic supply selection. Autom. Constr. 2020, 117, 103253. [CrossRef]

70. Sonmez, R.; Gürel, M. Hybrid Optimization Method for Large-Scale Multimode Resource-Constrained Project Scheduling Problem. J. Manag. Eng. 2016, 32, 04016020. [CrossRef]

71. Xu, J.; Liu, Q.; Lei, X. A fuzzy multi-objective model and application for the discrete dynamic temporary facilities location planning problem. J. Civ. Eng. Manag. 2016, 22, 357-372. [CrossRef]

72. Arashpour, M.; Wakefield, R.; Abbasi, B.; Lee, E.; Minas, J. Off-site construction optimization: Sequencing multiple job classes with time constraints. Autom. Constr. 2016, 71, 262-270. [CrossRef]

73. Gu, Q.; Xie, H.; Issa, R.R.A.; Lu, C. Location Optimization with Uncertainty for Industrial Project Using Discrete Block Model and Spatial Meshing Algorithm. J. Comput. Civ. Eng. 2019, 33, 04018064. [CrossRef]

74. Kerkhove, L.-P.; Vanhoucke, M. Optimised scheduling for weather sensitive offshore construction projects. Omega 2017, 66, 58-78. [CrossRef]

75. Li, H.; Wang, M.; Dong, X. Resource Leveling in Projects with Stochastic Minimum Time Lags. J. Constr. Eng. Manag. 2019, 145, 04019015. [CrossRef]

76. He, L.; Zhang, L. Dynamic priority rule-based forward-backward heuristic algorithm for resource levelling problem in construction project. J. Oper. Res. Soc. 2013, 64, 1106-1117. [CrossRef]

77. Hsu, P.-Y.; Aurisicchio, M.; Angeloudis, P. Risk-averse supply chain for modular construction projects. Autom. Constr. 2019, 106, 102898. [CrossRef]

78. Hassan, A.; El-Rayes, K.; Attalla, M. Optimizing the scheduling of crew deployments in repetitive construction projects under uncertainty. Eng. Constr. Arch. Manag. 2020. [CrossRef]

79. Nadoushani, Z.S.M.; Akbarnezhad, A.; Rey, D. Optimization of concrete placing operation based on competing carbon footprint, cost and production rate objectives. Eng. Constr. Arch. Manag. 2018, 25, 938-957. [CrossRef]

80. Wang, Z.; Hu, H.; Gong, J. Framework for modeling operational uncertainty to optimize offsite production scheduling of precast components. Autom. Constr. 2018, 86, 69-80. [CrossRef]

81. Cheng, M.-Y.; Chang, N.-W. Dynamic construction material layout planning optimization model by integrating 4D BIM. Eng. Comput. 2018, 35, 703-720. [CrossRef]

82. He, W.; Shi, Y.; Kong, D. Construction of a 5D duration and cost optimisation model based on genetic algorithm and BIM. J. Eng. Des. Technol. 2019, 17, 929-942. [CrossRef]

83. Ma, G.; Liu, X. Model and Algorithm for Dependent Activity Schedule Optimization Combining with BIM. Adv. Civ. Eng. 2020, 2020, 9727256. [CrossRef]

84. Ke, H.; Liu, B. Project scheduling problem with stochastic activity duration times. Appl. Math. Comput. 2005, 168, 342-353. [CrossRef]

85. Roofigari-Esfahan, N.; Razavi, S. Uncertainty-Aware Linear Schedule Optimization: A Space-Time Constraint-Satisfaction Approach. J. Constr. Eng. Manag. 2017, 143, 04016132. [CrossRef]

86. Xu, Y.; Wei, Y. Study on trade-off of time-cost-quality in construction project based on BIM. In 2015 International Conference on Economics, Social Science, Arts, Education and Management Engineering; Atlantis Press: Paris, France, 2015; Volume 38, pp. 864-870.

87. Zhou, R.; Ye, C.-M.; Ma, H.-M. Model Research of Multi-Objective and Resource-Constrained Project Scheduling Problem. In The 19th International Conference on Industrial Engineering and Engineering Management; Springer: Berlin/Heidelberg, Germany, 2013; Volume 2013, pp. 991-1001.

88. Abotaleb, I.; Nassar, K.; Hosny, O. Layout optimization of construction site facilities with dynamic freeform geometric representations. Autom. Constr. 2016, 66, 15-28. [CrossRef]

89. Huang, Y.; Qiu, Z.; Zhang, W. Network comprehensive optimization for schedule and cost in project construction based on PSO algorithm. In Proceedings of the 2008 IEEE International Conference on Automation and Logistics, Qingdao, China, 1-3 September 2008; Volume 2008, pp. 1260-1264.

90. Jaśkowski, P.; Sobotka, A.; Czarnigowska, A. Decision model for planning material supply channels in construction. Autom. Constr. 2018, 90, 235-242. [CrossRef]

91. Bakry, I.; Moselhi, O.; Zayed, T. Optimized scheduling and buffering of repetitive construction projects under uncertainty. Eng. Constr. Arch. Manag. 2016, 23, 782-800. [CrossRef]

92. Roghabadi, M.A.; Moselhi, O. Optimized crew selection for scheduling of repetitive projects. Eng. Constr. Arch. Manag. 2020. [CrossRef]

93. Yildirim, H.A.; Akcay, C. Time-cost optimization model proposal for construction projects with genetic algorithm and fuzzy logic approach. Rev. Constr. 2019, 18, 554-567. [CrossRef] 
94. Pan, N.-H. A hybrid optimization mechanism for constructing a dynamic simulation system-An operational behavior analysis of a moving scaffolding system. Autom. Constr. 2009, 18, 881-893. [CrossRef]

95. Xu, J.; Meng, J.; Zeng, Z.; Wu, S.; Shen, M. Resource Sharing-Based Multiobjective Multistage Construction Equipment Allocation under Fuzzy Environment. J. Constr. Eng. Manag. 2013, 139, 161-173. [CrossRef]

96. Xu, J.; Li, Z. Multi-Objective Dynamic Construction Site Layout Planning in Fuzzy Random Environment. Autom. Constr. 2012, 27, 155-169. [CrossRef]

97. $\mathrm{Xu}, \mathrm{J} . ;$ Feng, C. Two-stage based dynamic earth-rock transportation assignment problem under fuzzy random environment to earth-rock dam construction. J. Civ. Eng. Manag. 2015, 21, 775-797. [CrossRef]

98. Zhong, D.; Ren, B.; Li, M.; Wu, B.; Li, M. Theory on real-time control of construction quality and progress and its application to high arc dam. Sci. China Ser. E Technol. Sci. 2010, 53, 2611-2618. [CrossRef]

99. Hu, W.; Zhong, D.; Wu, B.; Li, Z. Construction phase oriented dynamic simulation: Taking RCC dam placement process as an example. J. Civ. Eng. Manag. 2019, 25, 654-672. [CrossRef]

100. Akhavian, R.; Behzadan, A.H. Construction equipment activity recognition for simulation input modeling using mobile sensors and machine learning classifiers. Adv. Eng. Inform. 2015, 29, 867-877. [CrossRef]

101. Špačková, O.; Straub, D. Dynamic Bayesian Network for Probabilistic Modeling of Tunnel Excavation Processes. Comput. Civ. Infrastruct. Eng. 2012, 28, 1-21. [CrossRef]

102. Gelisen, G.; Griffis, F.H. Automated Productivity-Based Schedule Animation: Simulation-Based Approach to Time-Cost Trade-Off Analysis. J. Constr. Eng. Manag. 2014, 140, B4013007. [CrossRef]

103. Srour, F.J.; Kiomjian, D.; Srour, I.M. Automating the Use of Learning Curve Models in Construction Task Duration Estimates. J. Constr. Eng. Manag. 2018, 144, 04018055. [CrossRef]

104. Damnjanovic, I.; Reinschmidt, K. Bayesian Revision of Probability Estimates. In Data Analytics for Engineering and Construction Project Risk Management; Springer: Cham, Switzerland, 2020; pp. 207-233. 